\title{
Living or deceased-donor kidney transplant: the role of psycho- socioeconomic factors and outcomes associated with each type of transplant
}

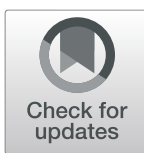

Abbas Basiri ${ }^{1}$, Maryam Taheri ${ }^{*}$, Alireza Khoshdel ${ }^{3}$, Shabnam Golshan ${ }^{1}$, Hamed Mohseni-rad ${ }^{4}$, Nasrin Borumandnia ${ }^{2}$, Nasser Simforoosh ${ }^{1}$, Mohsen Nafar ${ }^{5}$, Majid Aliasgari ${ }^{1}$, Mohammad Hossein Nourbala $^{6}$, Gholamreza Pourmand ${ }^{7}$, Soudabeh Farhangi ${ }^{8}$ and Nastaran Khalili ${ }^{1}$

\begin{abstract}
Background: Kidney transplant improves patients' survival and quality of life. Worldwide, concern about the equality of access to the renal transplant wait-list is increasing. In Iran, patients have the choice to be placed on either the living or deceased-donor transplant wait-list.
\end{abstract}

Methods: This was a prospective study performed on 416 kidney transplant recipients ( $n=217$ (52.2\%) from living donors and $n=199$ (47.8\%) from deceased donors). Subjects were recruited from four referral kidney transplant centers across Tehran, Iran, during 2016-2017. The primary outcome was to identify the psycho-socioeconomic factors influencing the selection of type of donor (living versus deceased). Secondary objective was to compare the outcomes associated with each type of transplant. The impact of psycho-socioeconomic variables on selecting type of donor was evaluated by using multiple logistic regression and the effect of surgical and non-surgical variables on the early post-transplant creatinine trend was assessed by univariate repeated measure ANOVA.

Results: Based on standardized coefficients, the main predictors for selecting living donor were academic educational level (adjusted $\mathrm{OR}=3.25,95 \% \mathrm{Cl}: 1.176-9.005, p=0.023$ ), psychological status based on general health questionnaire (GHQ) (adjusted $\mathrm{OR}=2.46,95 \% \mathrm{Cl}$ : 1.105-5.489, $p=0.028$ ), and lower monthly income (adjusted $\mathrm{OR}=$ 2.20, 95\% Cl: 1.242-3.916, $p=0.007$ ). The waiting time was substantially shorter in patients who received kidneys from living donors $(p<0.001)$. The early post-transplant creatinine trend was more desirable in recipients of living donors $(\beta=0.80,95 \% \mathrm{Cl}: 0.16-1.44, p$-value $=0.014)$, patients with an ICU stay of fewer than five days $(\beta=-0.583$, $95 \% \mathrm{Cl}:-0.643--0.522, p-v a l u e=<0.001)$, and those with less dialysis duration time $(\beta=0.016,95 \% \mathrm{Cl}: 0.004-0.028$, $p$-value $=0.012$. Post-operative surgical outcomes were not different across the two groups of recipients $(p=0.08)$, however, medical complications occurred considerably less in the living-donor group $(p=0.04)$.

(Continued on next page)

\footnotetext{
*Correspondence: taheri233@yahoo.com; taherim@sbmu.ac.ir

¿Urology and Nephrology Research Center (UNRC), Shahid Beheshti University of Medical Sciences, Tehran, Iran

Full list of author information is available at the end of the article
}

\section{$\triangle B M C$}

(c) The Author(s). 2020 Open Access This article is licensed under a Creative Commons Attribution 4.0 International License, which permits use, sharing, adaptation, distribution and reproduction in any medium or format, as long as you give appropriate credit to the original author(s) and the source, provide a link to the Creative Commons licence, and indicate if changes were made. The images or other third party material in this article are included in the article's Creative Commons licence, unless indicated otherwise in a credit line to the material. If material is not included in the article's Creative Commons licence and your intended use is not permitted by statutory regulation or exceeds the permitted use, you will need to obtain permission directly from the copyright holder. To view a copy of this licence, visit http://creativecommons.org/licenses/by/4.0/ The Creative Commons Public Domain Dedication waiver (http://creativecommons.org/publicdomain/zero/1.0/) applies to the data made available in this article, unless otherwise stated in a credit line to the data. 
(Continued from previous page)

Conclusion: Kidney transplant from living donors was associated with shorter transplant wait-list period and better early outcome, however, inequality of access to living donors was observed. Patients with higher socioeconomic status and higher level of education and those suffering from anxiety and sleep disorders were significantly more likely to select living donors.

Keywords: Deceased donor, Living donor, Kidney transplant, Psychologic status, Socioeconomic

\section{Introduction}

Currently, there is a global concern regarding inequality of access to the renal transplant waiting list [1]. Socioeconomic disparities influence the access to the kidney transplant wait-list in different parts of the world $[1,2]$. In the United Kingdom and the USA, access to the transplant waiting list is limited for deprived patients, while in France, patients with a low socioeconomic status have an equal access [3-5]. Due to national insurance policies in Iran, complete cost coverage is not feasible for every patient, thus patients' socioeconomic status plays an important role in donor type selection.

In Iran, patients in need of kidney transplants are placed on two separate wait-lists, based on the type of donor they select, living versus deceased donors. Thus far, studies have provided evidence that the outcome of living-donor transplant is superior to receiving kidneys from deceased donors [6-9]. This has led to the increasing attention and desire for recipients to opt for living unrelated donor transplants.

Several factors contribute to this preference including psychological and socioeconomic factors. Among psychological variables, anxiety and depression pose unique challenges in the course and prognosis of a disease, as well as its management [10-14]. The relatively prevalent coexistence of anxiety and depressive disorders with chronic medical conditions has diverse clinical consequences on treatment-seeking patterns and management strategies $[15,16]$. Considering the fact that kidney transplant candidates have to wait for a considerably long time before receiving a graft, this anticipation makes them prone to psychiatric issues such as depression and anxiety [17-19].

Although Iran was the first country to establish a living unrelated donor program in 1988 and living kidney donation has been performed frequently since then, a multicenter analysis comparing the psychosocioeconomic status of recipients of living and deceased donors is not yet available [20-22]. Moreover, although previous studies have shown the necessity of psychosocial screening in patients awaiting transplant for selecting the best potential recipients, there is lack of data regarding the role of psycho-socioeconomic factors on selecting the best type of donor [23]. Thus, the primary objective of this study was to investigate psycho- socioeconomic factors influencing patients' decision of choosing type of donor in Iran. We also assessed the early outcomes associated with each type of transplant.

\section{Objectives}

The primary outcome of this study was to identify the psychological and socioeconomic factors which influence the selection of type of donor (living versus deceased). The secondary objectives were to compare the early medical and surgical outcomes associated with each type of transplant, identify predictive factors of early posttransplant creatinine trend (as a marker of kidney function) and also estimate the mean waiting time for each type of kidney transplant while on the transplant waitlist.

\section{Methods}

\section{Design and setting}

This was a prospective cohort study conducted on patients undergoing kidney transplant regardless of etiology. Patients were recruited from one of the four transplant centers across Tehran including; Labbafinejad hospital, Baqiatallah hospital, Sina hospaital and Modarres hospital, during 2016-2017. Selection of hospitals was based on the following criteria:

- The center had to be a referral center located in Tehran, Iran.

- The center had to be a university hospital affiliated to one of the medical universities of Tehran, Iran.

- The staff of the center had to be willing to participate in this study and cooperate in sample collection.

\section{Study participants}

Eligible subjects included patients aged $\geq 18$ years old receiving a kidney transplant during 2016-2017, in one of the four centers mentioned above. A total of 416 recipients including 217 patients (52.2\%) receiving grafts from living donors and 199 (47.8\%) receiving deceased-donor transplants were included. The sampling approach was based on a three-month pilot study performed before the initiation of the actual study with the aim to estimate the number of transplants performed in each center and determine the dominant type of transplantation 
(deceased vs living) in that center. Then, based on probability proportional to size (PPS) sampling, the number of subjects required from each center was calculated. In the next step, sample recruitment started with both types of transplants. When the number of samples of the dominant type of transplant (in each specific center) reached approximately half of the required total sample size, no more samples of this type of transplant were included and recruitment would continue with the less frequent type of donor until the total sample size was reached. This ensured that within a particular timeframe, a proportionate number of living and deceaseddonor transplant recipients would be included without intentionally or non-intentionally excluding any cases. Also, the adjustment of the proportion of living and deceased kidney transplant recipients allowed for a more reliable comparison.

\section{Data collection}

Medical files and questionnaires were used to collect demographic, psycho-socioeconomic, and clinical data of patients before kidney transplant. Data regarding posttransplant clinical outcome of patients (medical and surgical) was collected by an independent investigator on day $1,3,5,7$, and 11 after transplant and eventually on the day of discharge based on history taking, physical examination, lab data, imaging and medical records. The indicators of socioeconomic position included employment status, health insurance, financial support, predialysis income and education level of recipients one year before dialysis start. Time to kidney transplant was defined as time from placement on the waiting list to the date of the transplant. Income was calculated as individual (after-tax) disposable income including from work and benefits and was categorized according to the consensus of the Iranian Ministry of Cooperative, Labor, and Social Welfare. Financial support was considered as any financial assistance from family, relatives, or nongovernmental organizations.

The translated General Health Questionnaire-28 (GHQ-28) was used for assessing mental symptoms and psychosocial well-being of the recipients [24]. According to Social Support Questionnaire (SSQ), three different source of support including family, friends, and significant others were evaluated [25]. Also, the translated 36Item Short Form Health Survey questionnaire (SF-36) was applied to evaluate health-related quality of life [26]. Validity and reliability of the Persian version of these questionnaires has been approved in the Iranian population $[27,28]$.

\section{Statistical analysis}

Continuous variables were presented as mean (standard deviation) and categorical variables were reported as frequencies (percentage). The independent t-test or Mann-Whitney were used to examine the association between quantitative variables, and Chi-Square or Fisher's Exact test were used for assessing categorical variables. The impact of psycho-socioeconomic variables on selecting the type of donor were evaluated using the multiple logistic regression with backward approach. Results are reported as odds ratio (OR) with 95\% confidence interval (CI) and $p$-values. Also, the importance of variables was determined by computing the standardized coefficient. Univariate repeated measure ANOVA assessed the effect of surgical and non-surgical variables on the early post-transplant creatinine trend. Subsequently, variables with a p-value less than 0.05 entered the multivariable generalized estimating equation (GEE) model. Finally, to identify predictive factors on the difference between serum creatinine before transplant and on the day of discharge, multivariate linear regression analysis was performed. All statistical analysis was performed using the SPSS software version 14.0 (IBM, Chicago, Illinois, USA) and also the 'reghelper' package in R software. $P$-value less than 0.05 was considered statistically significant.

\section{Ethical approval}

Written informed consent was obtained from participants before being enrolled in the study. The Ethics Committee of the Urology and Nephrology Research Center of Shahid Beheshti University of Medical Sciences (ethics code: UNRC.SBMU.931223.1) approved this study.

\section{Results}

Analysis was conducted on 416 recipients. Among the total participants, $68 \%(n=248)$ were male. There was no statistically significant difference between the two groups of recipients in terms of gender $(p=0.34)$. The mean age of the patients transplanted with living and deceased donors was $42.56(\mathrm{SD}=15.87)$ and $40.45(\mathrm{SD}=$ 16.0) years old, respectively $(p=0.13)$. The mean duration of dialysis was $14.7(\mathrm{SD}=17.1)$ months in recipients of living and $17.9(\mathrm{SD}=22.6)$ months in recipients of deceased donors $(p=0.11)$. Also, the mean wait-list period for kidney transplant was significantly shorter in recipients of living compared to deceased kidney donors (7.05 vs. 11.27 months, $p<0.001)$.

\section{Socioeconomic and psychological characteristics of the recipients}

As shown in Table 1, recipients' ethnicity, academic level of education, employment status, and monthly income were found to significantly influence the choice of selecting living or deceased donors $(p=0.008,0.002$, $0.002,<0.001$, respectively). Regarding the four main 
Table 1 Demographic, psycho-socioeconomic and clinical characteristics of recipients based on living or deceased donor

\begin{tabular}{lll}
\hline Living & Deceased & $\boldsymbol{p}$ value \\
$(\boldsymbol{n}=217)$ & $(\boldsymbol{n}=199)$ & \\
$\mathrm{N}(\%)$ & $\mathrm{N}(\%)$ & \\
& &
\end{tabular}

Age (years) ${ }^{\S}$

mean (SD)

$42.56(15.87) \quad 40.45(16.00) \quad .13$

Gender $^{\dagger}$

Male

Female

$153(70.5) \quad 131(65.8) \quad .34$

Ethnicity ${ }^{\dagger}$

Fars

Turk

Kurd

Arab

Lur

Other

Education $^{\ddagger}$

Illiterate

Elementary or high school

Diploma

Academic degree

Not declared

Employment $\neq$

Full time

Part time

Self employed

Unemployed

Retired

Disabled person

Not declared

Monthly income ${ }^{\text {a f }}$

Low income

Lower-middle income

Upper-middle income

Not declared

Health Insurance Coverage ${ }^{\dagger}$

Yes

No

Financial support ${ }^{\text {b }}$

Yes

No

\section{GHQ-28 questionnaire}

Somatic symptoms

Anxiety and sleep disorder

Social dysfunction

Depression symptoms
$121(55.7) \quad 128(64.32)$

$43(19.81) \quad 40(20.1)$

$21(9.67) \quad 5(2.51)$

$12(5.52) \quad 7(3.51)$

$6(2.76) \quad 11(5.52)$

$14(6.54) \quad 8(7.54)$

$28(13.3) \quad 36(18.7)$

$60(28.6) \quad 57(29.5)$

$71(33.8) \quad 80(41.5)$

$51(24.3) \quad 20(10.4)$

$7(3.22) \quad 6(3.01)$

$58(29.7) \quad 28(15.6)$

$16(8.2) \quad 19(10.6)$

$22(11.3) \quad 10(5.6)$

$66(33.8) \quad 89(49.7)$

$30(15.4) \quad 27(15.1)$

$3(1.5) \quad 6(3.4)$

$22(10.1) \quad 20(10.0)$

$81(43.1)$

$122(69.3)$

82 (43.6)

$43(24.4)$

25 (13.3)

$11(6.3)$

29 (13.3)

$23(11.5)$

213 (98.2) 191 (96.0)

$4(1.8) \quad 8(4.0)$

$83(45.4) \quad 81(49.7)$

$100(54.6) \quad 84(50.9)$

$164(42.3) \quad 137(35.3) \quad .162$

$168(43.3) \quad 136(35.1) \quad .044$

$79(20.4) \quad 81(20.9) \quad .290$

$145(37.5) \quad 147(37.9) \quad .045$

.002

.002
$64(29.5) \quad 68(34.2)$
Table 1 Demographic, psycho-socioeconomic and clinical characteristics of recipients based on living or deceased donor (Continued)

\begin{tabular}{llll}
\hline Living & Deceased & $\boldsymbol{p}$ value \\
$(\boldsymbol{n}=217)$ & $(\boldsymbol{n}=199)$ & \\
$\mathrm{N}(\%)$ & $\mathrm{N}(\%)$ & \\
\hline
\end{tabular}

\section{SF-36 questionnaire}

mean (SD)

Physical component summary

45.23 (16.24) 46.49 (15.36) 435

Mental component summary

$50.95(25.97) \quad 51.74(31.16) \quad .788$

Social Support Questionnaire ${ }^{\dagger}$

Family: Low or Moderate

$\begin{array}{lll}23(12.5) & 27(13.1) & .858 \\ 161(87.5) & 179(86.9) & \\ 73(35.4) & 60(32.6) & .556 \\ 133(64.4) & 124(67.4) & \end{array}$

High

Friends: Low or Moderate

$19(10.4)$

$25(12.4)$

.552

Significant other: Low or Moderate

$163(89.6)$

$177(87.6)$

ESRD causes ${ }^{\dagger}$

.22

Hypertension

$77(37.2) \quad 54(28.4)$

Diabetes Mellitus

$26(12.6) \quad 34(17.9)$

Glomerulonephritis

$33(15.9) \quad 24(12.7)$

Urologic diseases $^{b}$

$23(11.1) \quad 30(15.8)$

ADPKD

$13(6.3)$

$20(10.5)$

Others ${ }^{c}$ Unspecific

$45(21.0) \quad 37(19.4)$

ESRD: end stage renal disease, ADPKD: autosomal dominant polycystic kidney disease

a According to the consensus of the Iranian Ministry of Cooperative, labor, and social welfare, the minimum wage in 2016-2017 was approximately

10.000.000 Rials per month. Therefore, monthly income of recipients was divided into these tertiles: low income (monthly income: $<10.000 .000$ Rials), lower-middle income (between 10.000.000-20.000.000 Rials) and upper-middle income ( $>20.000 .000$ Rials)

${ }^{b}$ Financial support, any financial assistance from family, relatives, or non-governmental organizations

+ Chi Square Test

‡ Mann Whitney

$\S$ Independent sample T test

areas covered by the GHQ-28 questionnaire [24], anxiety and insomnia were reported to be higher among recipients of living donors $(p=0.044)$, while more patients receiving transplants from deceased donors suffered from depression symptoms $(p=0.045)$. Among the two distinct concepts of physical and mental health measured by the SF-36 questionnaire [29], there was no significant difference regarding the physical component summary (PCS) and the mental component summary (MCS) between living or deceased donor recipients $(p=0.435$ and $p=0.788$, respectively). Also, there were no difference between social support of the family, friends and significant others in the two groups of recipients based on the SSQ questionnaire. Table 1 shows results in detail.

The results of unadjusted analyses to determine predictive factors of donor type selection are presented in supplementary Table 1. Also, Table 2 presents the 
Table 2 Multiple logistic regression to determine predictive factors for selecting type of donor

\begin{tabular}{|c|c|c|c|c|}
\hline & \multirow{2}{*}{$\begin{array}{l}\text { Adjusted } \\
\mathrm{OR}\end{array}$} & \multicolumn{2}{|c|}{$95 \% \mathrm{Cl}$ for OR } & \multirow[t]{2}{*}{$p$-value } \\
\hline & & Lower & Upper & \\
\hline Age & 1.012 & .992 & 1.032 & .231 \\
\hline Gender (reference: male) & .840 & .440 & 1.604 & .598 \\
\hline \multicolumn{5}{|l|}{ Education (reference: illiterate) } \\
\hline Elementary to high school & .936 & .427 & 2.054 & .870 \\
\hline Diploma & 1.121 & .515 & 2.441 & .774 \\
\hline Academic & 3.254 & 1.176 & 9.005 & .023 \\
\hline \multicolumn{5}{|l|}{ Monthly income (reference: low income group) } \\
\hline Lower-middle income & 2.205 & 1.242 & 3.916 & .007 \\
\hline Upper-middle income & 2.847 & .937 & 8.651 & .065 \\
\hline Ethnicity (reference: other) & .617 & .357 & 1.066 & .084 \\
\hline Financial support (reference: yes) & .655 & .343 & 1.249 & .199 \\
\hline GHQ2 (reference: without anxiety and sleep disorder) & 2.462 & 1.105 & 5.489 & .028 \\
\hline GHQ4 (reference: without depression symptoms) & .702 & .335 & 1.471 & .349 \\
\hline SF-36: Physical component summary & 1.004 & .979 & 1.029 & .780 \\
\hline SF-36: Mental component summary & 1.005 & .989 & 1.022 & .519 \\
\hline SSQ family (reference: low + med) & .684 & .190 & 2.463 & .562 \\
\hline SSQ friend (reference: low + med) & .950 & .469 & 1.925 & .888 \\
\hline SSQ entourage (reference: low + med) & .996 & .267 & 3.715 & .995 \\
\hline ESRD causes (reference: DM + HTN) & .905 & .523 & 1.566 & .722 \\
\hline
\end{tabular}

OR, odds ratio. Cl, confidence interval. DM, diabetes mellitus. HTN, hypertension. GHQ, General Health questionnaire. SF-36, Short Form Health Survey-36 SSQ, Social support questionnaire. ESRD, End stage renal disease

results of adjusted analysis in detail. According to adjusted analysis, patients with academic education were almost 3.25 times more likely to select living-donors compared with the illiterate (OR $=3.41,95 \%$ CI: 1.17 9.00). There was an almost 2.2 times higher probability for patients belonging to the lower-middle income group to select living-donor transplant compared with the lowincome group $(\mathrm{OR}=2.2,95 \% \mathrm{CI}: 1.24-3.91)$. Moreover, those with anxiety and sleep disorder were almost 2.46 times more likely to receive living-donor transplant compared with patients without anxiety and sleep disorder $(\mathrm{OR}=2.46,95 \% \mathrm{CI}: 1.10-5.48)$. However, the GHQ4 was not significant in multiple logistic analysis, in unadjusted analysis those with depression symptoms were almost $40 \%$ less likely to receive living-donor transplant compared to those without depression symptoms. The other unadjusted results was similar and aligned with adjusted ones.

\section{Clinical outcomes of the kidney transplant}

The most common reasons for receiving kidney transplant among the total population were hypertension and diabetes mellitus (31.5 and $14.4 \%$ of all cases, respectively) (Table 1). Post-operative clinical status of all recipients including medical and surgical outcomes and laboratory tests is presented in Table 3. Post-operative surgical outcomes were not different across the two groups of recipients $(p=0.08)$, however, medical complications occurred considerably less in the living-donor group $(p=0.04)$.

In addition, the effect of non-surgical and surgical variables on the early postoperative creatinine trend was investigated (Figs. 1 \& 2). The multiple GEE model showed that donor type, duration of dialysis, and ICU stay of fewer than 5 days were predictive factors of posttransplant creatinine trend $(p=0.014,0.012$ and $<0.001$, respectively) (Table 4). Also, by performing multiple linear regression analysis with backward elimination, the effect of these variables on the difference between serum creatinine before transplant and on the day of discharge was explored. In this regard, living-donor kidney transplant was associated with a significantly higher decrease in post-transplant creatinine levels as compared to deceased donors $(p=0.027)$. Moreover, patients who were on peritoneal dialysis experienced less improvement in post-transplant serum creatinine level compared to those without a history of dialysis, although this difference was not statistically significant $(p=0.076)$.

\section{Discussion}

In this study, we investigated the role of patients' socioeconomic and psychologic condition on electing 
Table 3 Clinical outcome of recipients based on type of donor

\begin{tabular}{|c|c|c|c|}
\hline & Living $(\boldsymbol{n}=217)$ & Deceased $(\boldsymbol{n}=199)$ & $p$-value $\neq$ \\
\hline & $\mathrm{n}(\%)$ & n (\%) & \\
\hline Medical events & & & .04 \\
\hline Acute Rejection & $13(6)$ & $17(8.5)$ & .60 \\
\hline ATN & $36(16.6)$ & $54(27.13)$ & .03 \\
\hline DGF & $43(19.8)$ & $68(34.17)$ & .004 \\
\hline Arrhythmia & $7(3.22)$ & $7(3.5)$ & .97 \\
\hline Myocardial infarction & $0(0)$ & $7(3.5)$ & .02 \\
\hline Pulmonary emboli & $3(1.38)$ & $3(1.5)$ & .99 \\
\hline Infection & $9(4.15)$ & $6(3.01)$ & .82 \\
\hline Surgical events & & & .08 \\
\hline Hemorrhage & $10(4.6)$ & $8(4.02)$ & \\
\hline Vascular thrombosis & $1(0.46)$ & $5(2.51)$ & \\
\hline Ureteral complication & $3(1.38)$ & $3(1.5)$ & \\
\hline Surgical site infection & $2(0.92)$ & $3(1.5)$ & \\
\hline $\begin{array}{l}\text { Lab Data } \\
\text { mean (SD) }\end{array}$ & Before Transplant $\rightarrow$ After Transplant & Before Transplant $\rightarrow$ After Transplant & p-valuet \\
\hline $\mathrm{Hb}$ & $11.09(2.28) \rightarrow 10.05(1.72)$ & $11.54(2.03) \rightarrow 9.5(1.49)$ & .04 \\
\hline WBC & $10.40(14.7) \rightarrow 13.92(13.20)$ & $8.92(7.26) \rightarrow 10.39(6.59)$ & .22 \\
\hline PLT & $184.98(61.8) \rightarrow 189.61$ & $196.95(99.5) \rightarrow 186.36(66.0)$ & .15 \\
\hline AST & $17.47(9.11) \rightarrow 26.60(16.76)$ & $20.04(13.62) \rightarrow 89.26(7.65)$ & .03 \\
\hline ALT & $19.22(10.98) \rightarrow 43.71$ & $20.86(18.40) \rightarrow 40.91$ & .30 \\
\hline ALP & $286.43(226.26) \rightarrow 129.40(16.67)$ & $319.30(237.57) \rightarrow 131.38(14.90)$ & .19 \\
\hline
\end{tabular}

₹ Chi- square test

† Paired t-test

ESRD, end stage renal disease. ADPKD, autosomal dominant polycystic kidney disease. ATN, acute tubular necrosis. DGF, delayed graft function. Lab data, laboratory data. $\mathrm{Hb}$, hemoglobin. WBC, white blood cell. PLT, platelet. AST, aspartate aminotransferase. ALT, alanine aminotransferase. ALP, alkaline phosphatase

deceased or living donors. Our results revealed that patients with higher education and income tended to receive transplants from living donors more frequently. This was similar to the majority of studies showing that access to the kidney transplant waiting list is affected by higher level of education and socioeconomic deprivation [2-4, 30-32]. In addition, the results of our study showed that patients with insomnia and anxiety mostly desired transplant from living donors while patients with depression symptoms had a tendency for deceased donors.

Generally, kidney transplant candidates are prone to significant psychological distress in the transplant waitlist period. Previous studies have shown that dialysis patients anticipating deceased-donor transplant suffer from anxiety and depression during the transplant wait-list period [33]. Depression is the most common psychiatric issue among dialysis patients, mainly due to presence of multiple stressors in their lives. In one study, patients on dialysis had stated that while waiting for a transplant, "they felt their life was on hold and they had a sense of isolation", indicating the disparity and depression that patients on dialysis face [33]. Moreover, waiting for a deceased-donor transplant is associated with a great deal of uncertainty since both the timing and the outcome of the transplant are unknown. The unpredictable results of this operation can lead to an increased feeling of stress and anxiety. Regarding living-donor transplant, since the donor who is either a relative or someone with an altruistic motive for donating is usually known to the recipient, somewhat different experiences have been reported [33]. Thus, the dynamic of the relationship between the donor and the recipient alters the experience of waiting period. Also, in contrast to deceased-donor transplant, anticipating transplant from a living-donor is an active process with a definite outcome [33]. The findings of our study might be justified by the fact that anxious patients desire an immediate transplant with assured favorable outcome more than others. Although no study has compared the psychological status of deceased and living-donor recipients before transplant, a study in Iran showed that depression and anxiety are significantly higher in the deceased-donor group after transplant [34]. There have also been multiple studies 


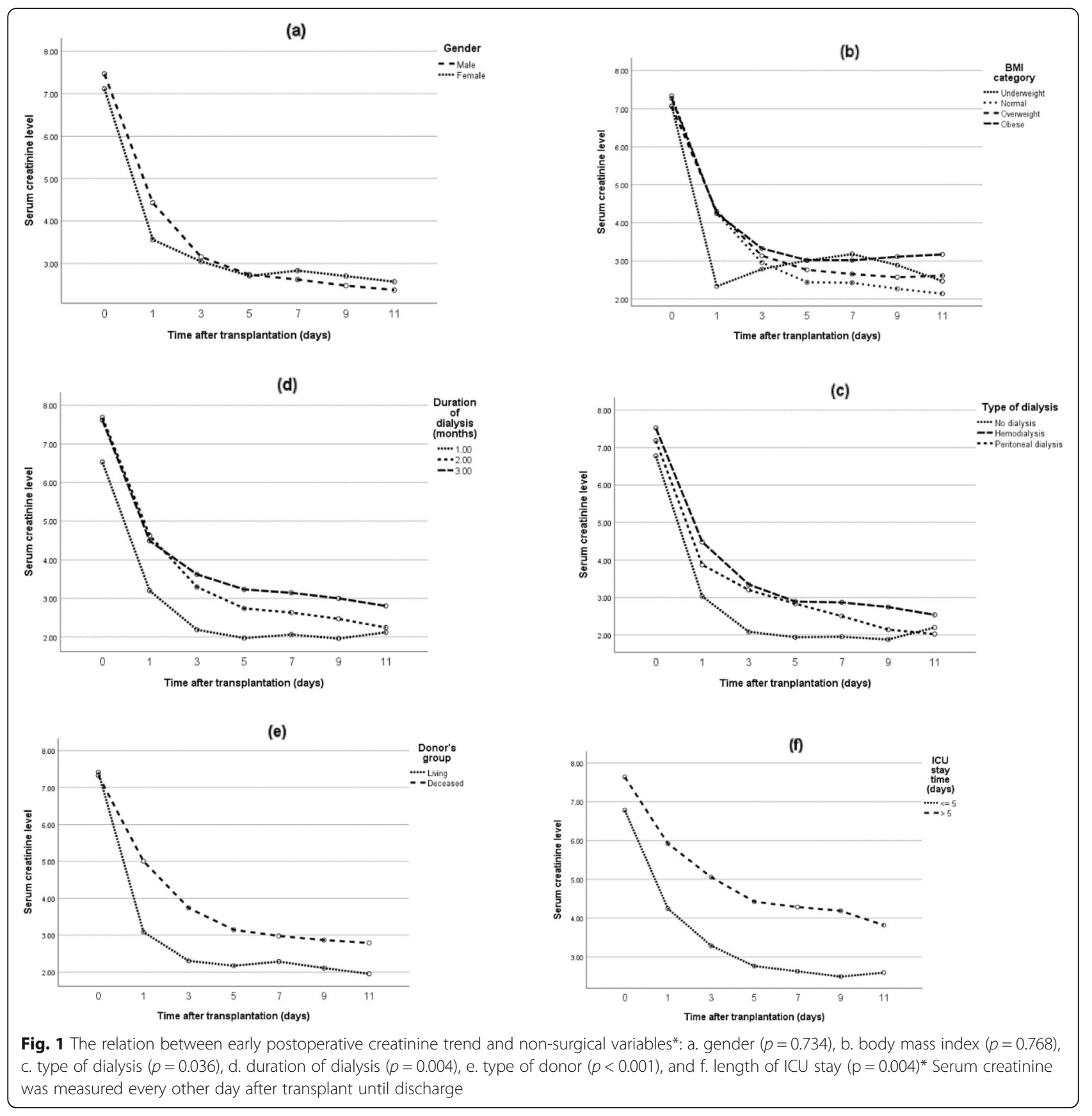

comparing psychological status of Iranian patients maintained on dialysis with those who have already received transplants, generally showing a lower anxiety score among transplant recipients compared to hemodialysis patients $[18,19]$.

In general, early post-transplant surgical complications are classified into three groups: vascular, urologic, and others. Vascular complications remain the major concern after kidney transplant with a reported incidence of 2 to $15 \%$. In a study by Ayvazoglu Soy et al., the incidence of vascular complications on 2594 kidney transplants (76\% living donors and 24\% deceased donors) was $2.1 \%$ [35], with the most common complication being renal artery stenosis $(0.6 \%)$. In another study by Ammi et al. on 312 kidney transplants, a vascular complication rate of $16.0 \%$ was reported [36]. Regarding urologic complications, in a study by Rasiliti and colleagues, the prevalence was reported to be $13.1 \%$ in 297 deceased kidney transplants [37]. Duty et al. reported this rate to be approximately $9 \%$ [38]. In the present study, we found the overall rate of surgical complications to be $9.13 \%$. Postoperative vascular and urologic 


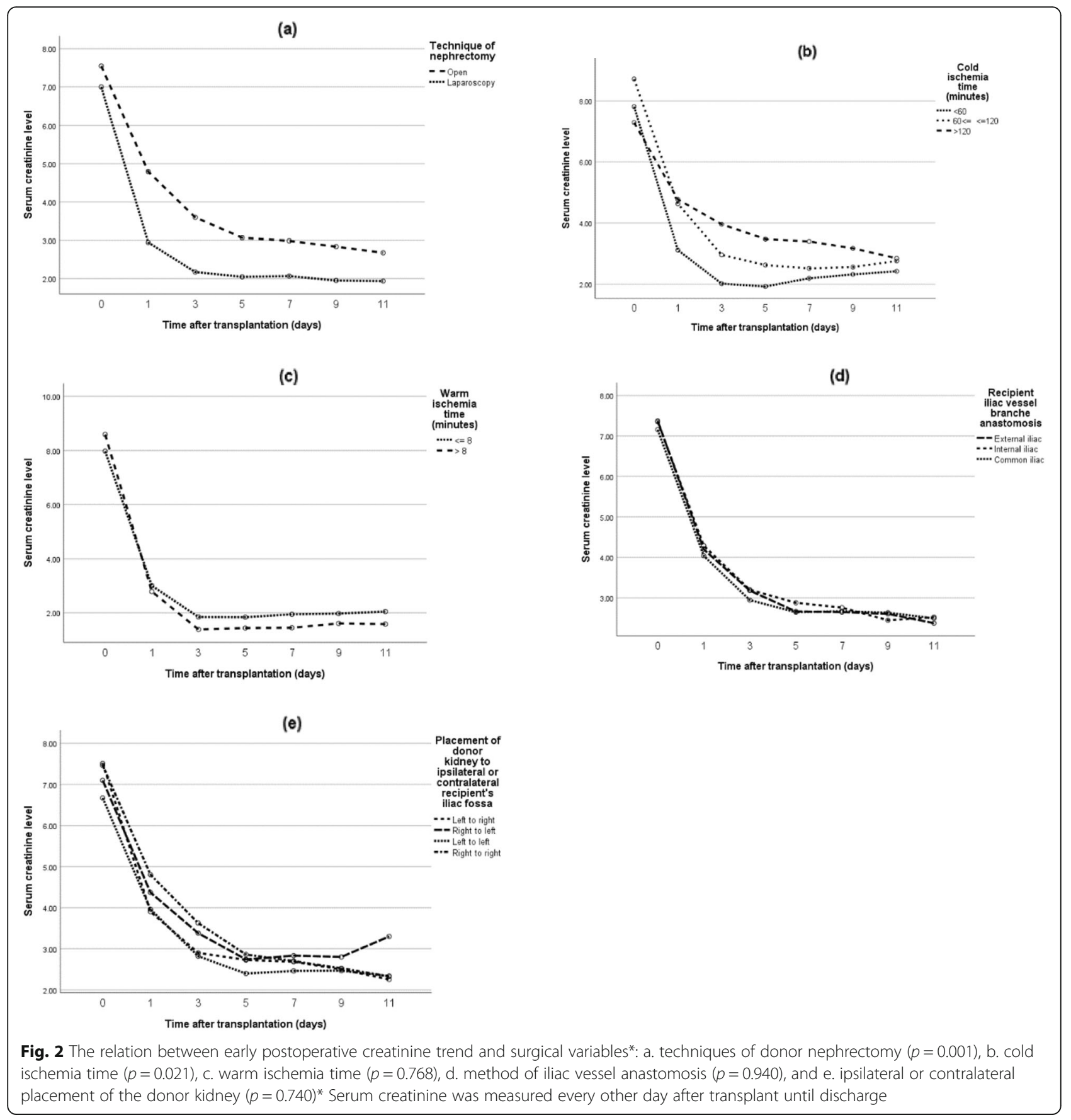

complications were observed in 5.8 and $1.5 \%$ of patients, respectively. Perhaps the lower rate of urologic complications in this study was due to the reason that kidney transplant is solely performed by urologists in Iran while elsewhere it is mostly performed by general surgeons. Nevertheless, although post-operative surgical outcomes were not different across the two groups of recipients in this study, medical problems were significantly more common in recipients of deceased donors and a higher prevalence of delayed graft function, acute tubular necrosis, and myocardial infarction were seen in these patients. In a study by Biag et al. performed on 63 patients with a mean follow-up duration of 14.05 months, infectious complications were the most common posttransplant adverse event [39]. There are limited studies about comparison of early postoperative complications; however, unscheduled surgical operation, more comorbidities, and possibly, less medical care received by recipients of deceased donors might explain the higher rate of medical complications in this group. 
Table 4 Multiple analysis on the difference between serum creatinine before transplant and on the day of discharge

\begin{tabular}{|c|c|c|c|c|}
\hline GEE model $^{\text {a }}$ & $\beta$ & Cl for $\beta$ & & $p$-value \\
\hline \multicolumn{5}{|c|}{ Type of donor } \\
\hline Living donor & .800 & .160 & 1.440 & .014 \\
\hline \multicolumn{5}{|l|}{ Deceased donor (reference) } \\
\hline \multicolumn{5}{|c|}{ Type of dialysis } \\
\hline Peritoneal dialysis & .241 & -.502 & .984 & .525 \\
\hline Hemodialysis & .399 & -.145 & .942 & .151 \\
\hline \multicolumn{5}{|l|}{ No dialysis (reference) } \\
\hline Cold ischemia time & .001 & -.007 & .009 & .843 \\
\hline Dialysis duration & .016 & .004 & .028 & .012 \\
\hline ICU stay duration & -.583 & -.643 & -.522 & $<0.001$ \\
\hline Linear regression analysis $b, c$ & $\beta$ & \multicolumn{2}{|c|}{$\mathrm{Cl}$ for $\beta$} & p-value \\
\hline Living donor (compared to deceased donor) & 1.062 & 0.144 & 1.998 & .027 \\
\hline Peritoneal dialysis (compared to no dialysis) & -1.233 & -2.593 & 0.119 & .076 \\
\hline
\end{tabular}

Beta: regression coefficient, SE: standard of error

${ }^{a}$ The dependent variable is creatinine across different time points

b Variable(s) entered in the analysis included: donor type, type of dialysis, duration of dialysis, cold ischemia time and duration of ICU stay

c The dependent variable is difference of serum creatinine before transplant and on the day of discharge

According to previous studies, risk factors of failure to reduce early post-transplant serum creatinine level include gender, BMI, type of dialysis, duration of dialysis, length of ICU stays, cold and warm ischemia time, and type of donor [40-42]. Our results showed that livingdonor transplant, ICU stay less than five days, cold ischemia time less than sixty minutes and hemodialysis or no history of dialysis before kidney transplant had a significant effect on post-transplant creatinine level. Also, among recipients of living donors, those who underwent laparoscopic nephrectomy technique had a better posttransplant creatinine trend.

Ours study also estimated the waiting time for kidney transplant in recipients of living donors (7.05 months) to be significantly less than that of deceased donors (11.27 months). Also, it seemed that living donor transplant in Iran renders less waiting time compared to other countries, possibly due to the active living donor program and high rate of deceased donation. The transplant waiting time in the USA is almost 4.72 years for recipients of deceased donors and in European countries, this time is about 2 to 5 years [43]. However, in Norway, where living donation is more frequent, the waiting time is 11 months [44].

Although this was not the intention of our study, we found that hypertension and diabetes mellitus were the most common factors attributing to end-stage renal disease (ESRD) in our study population. In line with this finding, the United States Renal Data System (USRDS) has reported diabetes mellitus and hypertension as the major causes of (overall 63\%), followed by glomerular diseases (14\%) [45]. However, there was a considerable difference in the prevalence of urologic etiologies
(13.45\%) in our study compared to the data of USRDS. This may be due to the reason that centers included in this study were referral transplant centers admitting recipients who are more complicated cases.

There were some limitations to our study:

1. Our socioeconomic data was based on self-reported questionnaires which may have been inaccurately reported.

2. The reported psychological status of patients might be affected by the method of assessment, for example, results might have been different based on the person who interviewed the patients (psychiatrist, psychologist, or unspecialized medical staff). In this study, the psychological questionnaires were filled in by an independent blind interviewer who were medical staff.

3. Some outcomes required a greater number of patients to reach a more precise conclusion. For example, vascular complications are not common, thus for a better comparison of this outcome in the two groups of recipients, a larger sample size would have been beneficial [46].

4. Data about human leukocyte antigen (HLA) matching was missing in our study. Since HLAmismatch affects the outcome of transplant and the post-transplant creatinine trend, we could not reach a definite conclusion in this regard [40].

\section{Conclusion}

This study reveals novel information about the existing psycho-socioeconomic disparities in Iran in terms of access to type of donor and the medical and surgical 
outcomes associated with each type of transplant. In summary, higher educational level, higher monthly income, and suffering from anxiety and sleep disorders (based on the GHQ-28) influenced the choice of selecting a living-donor transplant, which came with the benefit of less waiting time and better early post-transplant creatinine trend. Moreover, although post-operative surgical outcomes were not different across the two groups of recipients, medical complications occurred considerably less in the living-donor group. However, since the results associated with outcome of transplant might change over time in both groups, follow-up of these patients would be beneficial. Also, future studies to compare the psychological status of these two group of recipients after transplantation is recommended.

The findings of this comprehensive multicenter study will provide evidence for policymakers to implement strategies and specific actions for providing support to susceptible individuals who are either socioeconomically or psychologically less advantaged. Hopefully, this will allow for an equal opportunity to choose between living or deceased-donor transplant.

\section{Supplementary information}

Supplementary information accompanies this paper at https://doi.org/10. 1186/s12939-020-01200-9.

Additional file 1: Supplementary Table 1. Univariable logistic regression to determine predictive factors for selecting type of donor.

\section{Acknowledgements}

We wish to thank the medical staff at the transplant units of Labbafinejad hospital, Baqiatallah hospital, Sina hospaital and Modarres hospital.

\section{Informed consent}

Informed consent was obtained from all individual participants or their family members (in case of deceased donors) included in the study.

\section{Authors' contributions}

Abbas Basiri: Study design, supervision and final revision of the manuscript. Maryam Taheri: Overseeing the study, data collection and interpretation, manuscript writing. Alireza Khoshdel: Study design, and interpretation of results. Shabnam Golshan: Data collection and data integration of multiple centers. Hamed Mohseni-rad: Drafting and writing the manuscript. Nasrin Borumandnia: Analysis and interpretation of data. Nasser Simforoosh, Mohsen Nafar, Majid Aliasgari, Mohammad Hossein Nourbala, Gholamreza Pourmand and Soudabeh Farhangi: Data collection of different centers. Nastaran Khalili: Writing, revision and final editing of manuscript. The author(s) read and approved the final manuscript.

\section{Funding}

None.

\section{Availability of data and materials}

The datasets during and/or analyzed during the current study available from the corresponding author on reasonable request.

\section{Compliance with ethical standards}

Not applicable.

\section{Ethics approval and consent to participate}

All procedures performed were in accordance with the ethical standards of the Ethics Committee of the Urology and Nephrology Research Center of Shahid Beheshti University of Medical Sciences (ethics code:

UNRC.SBMU.931223.1) and with the 1964 Helsinki declaration and its later amendments or comparable ethical standards.

\section{Competing interests}

None declared.

\section{Author details}

'Urology and Nephrology Research Center (UNRC), Shahid Labbafinejad Medical Center, Shahid Beheshti University of Medical Sciences, Tehran, Iran. ${ }^{2}$ Urology and Nephrology Research Center (UNRC), Shahid Beheshti University of Medical Sciences, Tehran, Iran. ${ }^{3}$ Modern Epidemiology Research Center, Aja University of Medical Sciences, Tehran, Iran. ${ }^{4}$ Department of Urology, Ardabil University of Medical Sciences, Ardabil, Iran. ${ }^{5}$ Chronic Kidney Disease Research Center, Urology and Nephrology Research Center, Shahid Labbafinejad Medical Center, Shahid Beheshti University of Medical Sciences, Tehran, Iran. ${ }^{6}$ Baqiyatallah University of Medical Sciences, Tehran, Iran. ${ }^{7}$ Urology Research Center, Ibin Sina Medical Center, Tehran University of Medical Sciences, Tehran, Iran. ${ }^{8}$ Shahid Beheshti University of Medical Sciences, Tehran, Iran.

Received: 17 December 2019 Accepted: 26 May 2020

Published online: 01 June 2020

References

1. Kihal-Talantikite W, Vigneau C, Deguen S, Siebert M, Couchoud C, Bayat S. Influence of socio-economic inequalities on access to renal transplantation and survival of patients with end-stage renal disease. PLoS One. 2016;11: e0153431.

2. Zhang $Y$, Gerdtham UG, Rydell H, Jarl J. Socioeconomic inequalities in the kidney transplantation process: a registry-based study in Sweden. Transplant Direct. 2018;4:e346.

3. Dudley CR, Johnson RJ, Thomas HL, Ravanan R, Ansell D. Factors that influence access to the national renal transplant waiting list. Transplantation. 2009:88:96-102

4. Schold JD, Gregg JA, Harman JS, Hall AG, Patton PR, Meier-Kriesche HU. Barriers to evaluation and wait listing for kidney transplantation. Clin J Am Soc Nephrol. 2011;6:1760-7.

5. Bayat S, Macher M. Couchoud C, et al. Individual and regional factors of access to the renal transplant waiting list in France in a cohort of dialyzed patients. 2015;15:1050-60.

6. Lee S, Kim J, Shin M, et al. Comparison of outcomes of living and deceased donor kidney grafts surviving longer than 5 years in Korea. Transplant Proc. 2010:42:775-7.

7. Roodnat II, van Riemsdijk IC, Mulder PG, et al. The superior results of livingdonor renal transplantation are not completely caused by selection or short cold ischemia time: a single-center, multivariate analysis. Transplantation. 2003;75:2014-8

8. Nemati E, Einollahi B, Lesan Pezeshki M, Porfarziani V, Fattahi MR. Does kidney transplantation with deceased or living donor affect graft survival? Nephro-urology monthly. 2014;6:e12182-e.

9. Almasi-Hashiani A, Mansournia MA, Rezaeifard A, Mohammad K. Causal effect of donor source on survival of renal transplantation using marginal structural models. Iran J Public Health. 2018;47:706-12.

10. Lichtman JH, Bigger JT Jr, Blumenthal JA, et al. Depression and coronary heart disease: recommendations for screening, referral, and treatment: a science advisory from the American Heart Association prevention Committee of the Council on cardiovascular nursing. Council on Clinical Cardiology, Council on Epidemiology and Prevention, and Interdisciplinary Council on Quality of Care and Outcomes Research: endorsed by the American Psychiatric Association. 2008;1 18:1768-75.

11. Rahman R, Ibaseta A, Andrade NS, et al. P132. PROMIS depression and anxiety correlate with postoperative NASS satisfaction in cervical patients. 2019;19:5219.

12. Garcia RG, Mareckova K, Holsen LM, et al. Impact of sex and depressed mood on the central regulation of cardiac autonomic function. 20201-10. 
13. Machin AR, Babatunde $\mathrm{O}$, Haththotuwa $\mathrm{R}$, et al. The association between anxiety and disease activity and quality of life in rheumatoid arthritis: a systematic review and meta-analysis. 20201-12.

14. Wu C-S, Hsu L-Y, Wang S-HJE. Sciences P. Association of depression and diabetes complications and mortality: a population-based cohort study. 2020;29.

15. Jagtap N, Muliyala KP, Chaturvedi SK. Depression, anxiety, and physical morbidity in women. In: Chandra PS, Herrman H, Fisher J, Riecher-Rössler A, editors. Mental health and illness of women. Singapore: Springer Singapore; 2020. p. 259-79.

16. Ciechanowski PS, Katon WJ. Russo JEJAoim. Depression and diabetes: impact of depressive symptoms on adherence, function, and costs. 2000; 160:3278-85

17. Szeifert L, Molnar MZ, Ambrus C, et al. Symptoms of depression in kidney transplant recipients: a cross-sectional study. Am J Kidney Dis. 2010;55:132-40.

18. Alavi N, Aliakbarzadeh Z, Sharifi K. Depression, anxiety, activities of daily living, and quality of life scores in patients undergoing renal replacement therapies. Paper presented at: Transplantation proceedings. 2009.

19. Karaminia R, Tavallaii S, Lorgard-Dezfuli-Nejad M, et al. Anxiety and depression: a comparison between renal transplant recipients and hemodialysis patients. Paper presented at: Transplantation proceedings. 2007

20. Rodrigue JR, Cornell DL, Lin JK, Kaplan B, Howard RJ. Increasing live donor kidney transplantation: a randomized controlled trial of a home-based educational intervention. Am J Transplant. 2007;7:394-401.

21. Simforoosh N, Basiri A, Fattahi MR, et al. Living unrelated versus living related kidney transplantation: 20 years' experience with 2155 cases. Transplant Proc. 2006;38:422-5.

22. Ghods AJ. Renal transplantation in Iran. Nephrology Dialysis Transplantation. 2002;17:222-8

23. Bunzel B, Laederach-Hofmann K. Solid organ transplantation: are there predictors for Posttransplant noncompliance? A Literature Overview Transplantation. 2000;70:711-6.

24. Goldberg DP, Hillier VF. A scaled version of the general health questionnaire. Psychol Med. 2009;9:139-45.

25. Zimet GD, Dahlem NW, Zimet SG, Farley GK. The multidimensional scale of perceived social support. J Pers Assess. 1988;52:30-41.

26. Lins L, Carvalho FM. SF-36 total score as a single measure of health-related quality of life: scoping review. SAGE open medicine. 2016:4: 2050312116671725.

27. Noorbala A, Mohammad K. The validation of general health questionnaire28 as a psychiatric screening tool. Hakim Research Journal. 2009;11:47-53.

28. Montazeri A, Goshtasebi A, Vahdaninia M, Gandek B. The short form health survey (SF-36): translation and validation study of the Iranian version. Qual Life Res. 2005;14:875-82.

29. Suzuki A, Kenmochi T, Maruyama M, et al. Changes in quality of life in deceased versus living-donor kidney transplantations. Transplant Proc. 2012; 44:287-9.

30. Waterman AD, Morgievich M, Cohen DJ, et al. Living donor kidney transplantation: improving education outside of transplant centers about live donor transplantation--recommendations from a consensus conference. Clin J Am Soc Nephrol. 2015;10:1659-69.

31. Schaeffner ES, Mehta J. Winkelmayer WCJAjokd. Educational level as a determinant of access to and outcomes after kidney transplantation in the United States. 2008;51:811-8.

32. Oniscu GC, Schalkwijk AA, Johnson RJ, Brown H. Forsythe JLJB. Equity of access to renal transplant waiting list and renal transplantation in Scotland: cohort study. 2003:327:1261.

33. Burns T, Fernandez R, Stephens M. The experiences of adults who are on dialysis and waiting for a renal transplant from a deceased donor: a systematic review. JBI Database System Rev Implement Rep. 2015;13:169-211.

34. Parsaei Mehr Z, Hami M, Moshtagh EZ. Anxiety and depression: a comparison between living and cadaveric renal transplant recipients. Int J Organ Transplant Med. 2011;2:178-83.

35. Ayvazoglu Soy EH, Akdur A, Kirnap M, Boyvat F, Moray G, Haberal M. Vascular complications after renal transplant: a single-center experience. Exp Clin Transplant. 2017;15:79-83.

36. Ammi M, Daligault M, Sayegh J, et al. Evaluation of the vascular surgical complications of renal transplantation. Ann Vasc Surg. 2016:33:23-30.
37. Risaliti A, Sainz-Barriga M, Baccarani U, et al. [Surgical complications after kidney transplantation]. G Ital Nefrol. 2004;21 Suppl 26:S43-7.

38. Duty BD, Barry JM. Diagnosis and management of ureteral complications following renal transplantation. Asian J Urol. 2015;2:202-7.

39. Baig ZF, Siddiqui UA, Mahmood A, Sabir H, Tareen TB. Medical complications of renal transplant - 2 Years' experience at armed forces institute of urology. J Ayub Med Coll Abbottabad. 2018;30:345-50.

40. Irish WD, Ilsley JN, Schnitzler MA, Feng S, Brennan DC. A risk prediction model for delayed graft function in the current era of deceased donor renal transplantation. Am J Transplant. 2010;10:2279-86.

41. Nashan B, Abbud-Filho M, Citterio F. Prediction, prevention, and management of delayed graft function: where are we now? Clin Transpl. 2016:30:1198-208.

42. Zaza G, Ferraro PM, Tessari G, et al. Predictive model for delayed graft function based on easily available pre-renal transplant variables. Intern Emerg Med. 2015;10:135-41.

43. Davis AE, Mehrotra S, McElroy LM, et al. The extent and predictors of waiting time geographic disparity in kidney transplantation in the United States. Transplantation. 2014;97:1049-57.

44. Stel VS, Kramar R, Leivestad T, et al. Time trend in access to the waiting list and renal transplantation: a comparison of four European countries. Nephrol Dial Transplant. 2012:27:3621-31.

45. Collins AJ, Foley RN, Gilbertson DT, Chen S-C. United States renal data system public health surveillance of chronic kidney disease and end-stage renal disease. Kidney international supplements. 2015;5:2-7.

46. Aktas S, Boyvat F, Sevmis S, Moray G, Karakayali H, Haberal M. Analysis of vascular complications after renal transplantation. Transplant Proc. 2011;43: $557-61$

\section{Publisher's Note}

Springer Nature remains neutral with regard to jurisdictional claims in published maps and institutional affiliations.

Ready to submit your research? Choose BMC and benefit from:

- fast, convenient online submission

- thorough peer review by experienced researchers in your field

- rapid publication on acceptance

- support for research data, including large and complex data types

- gold Open Access which fosters wider collaboration and increased citations

- maximum visibility for your research: over $100 \mathrm{M}$ website views per year

At $\mathrm{BMC}$, research is always in progress.

Learn more biomedcentral.com/submissions 